\title{
Modifications to a rainfall-streamflow model to handle "non-stationarity"
}

\author{
B. F. W. Croke ${ }^{1,2}$ and M.-J. Shin ${ }^{1,3}$ \\ ${ }^{1}$ National Centre for Groundwater Research and Training, Fenner School for Environment and Society, \\ Australian National University, Canberra, Australia \\ ${ }^{2}$ Mathematical Sciences Institute, Australian National University, Canberra, Australia \\ ${ }^{3}$ Research Group for Climate Change Adaptation in Water Resources, Seoul National University, Seoul, \\ South Korea
}

Correspondence to: B. F. W. Croke (barry.croke@ anu.edu.au)

Received: 12 March 2015 - Accepted: 12 March 2015 - Published: 12 June 2015

\begin{abstract}
This paper explores the variation in hydrological response (often termed as non-stationarity, though this is not necessarily the correct use in the statistical meaning of this term) through time for the Bani catchment in Africa (mostly located in Mali). The objective is to identify deficiencies in the ability of the model to capture the variation in the hydrologic response of the catchment, and modify the model to capture this variation. Due to the large catchment area (approximately $103000 \mathrm{~km}^{2}$ ), the unit hydrograph component of the model was modified to permit the model to be used at a daily timescale. Further, an additional driver (population growth) needed to be included in order to adequately capture the transition from a perennial to an ephemeral river.
\end{abstract}

\section{Introduction}

Predicting future water resources requires determining what drivers of hydrological response might change, and how those drivers can be represented in the model. Generally, the focus is on climate change (e.g. observations of the impact of the Millenium drought in south-eastern Australia, Chiew et al., 2014). However, other drivers may also be significant (e.g. changes in land use, population, demographics, ...), and there is increasing emphasis on capturing these drivers (e.g. Peel and Blöschl, 2011). The impact of these drivers is instability in the parameters of hydrological models (Brigode et al., 2013), leading to the need for a means of validating model parameter values under changed conditions (see Refsgaard et al., 2014 for a suggested framework for achieving this).

This paper investigates a catchment which has a significant change in hydrological condition over the available period of record, with a decline in rainfall and the river transitioning from perennial to ephemeral. The IHACRES rainfall-runoff model (Jakeman et al., 1990; Croke and Jakeman, 2004; Andrews et al., 2011) has been used as the starting point for this study, exploring possible changes to the model structure that enable the model to capture the change in hydrological behaviour of the catchment without the need to vary the model parameters.

\section{Bani catchment, Mali}

Streamflow data for the Bani catchment from a gauge located near Douna, Mali (approximately $103000 \mathrm{~km}^{2}$ ), about $230 \mathrm{~km} \mathrm{SW}$ of the confluence with the Niger River (Ruelland et al., 2012) has been used to investigate the variation in the catchment response between 1959 and 1990, with 6 five-year calibration periods used (starting in 1961, 1966, 1973, 1978, and 1983), with a 2-year period (1959-1960) used to spinup the model. Rainfall and streamflow data (Rueland et al., $2008,2012)$ and estimates of potential evaporation using the approach of Oudin et al. (2005) have been used to explore the temporal variation in the hydrological response of the catchment. This data has been supplemented by an estimate of the average population density across the catchment using the variation between 1960 and 1990 for three study areas in the region (Ruelland et al., 2010). Assuming an equal weighted average of the three areas as being representative of the pop- 

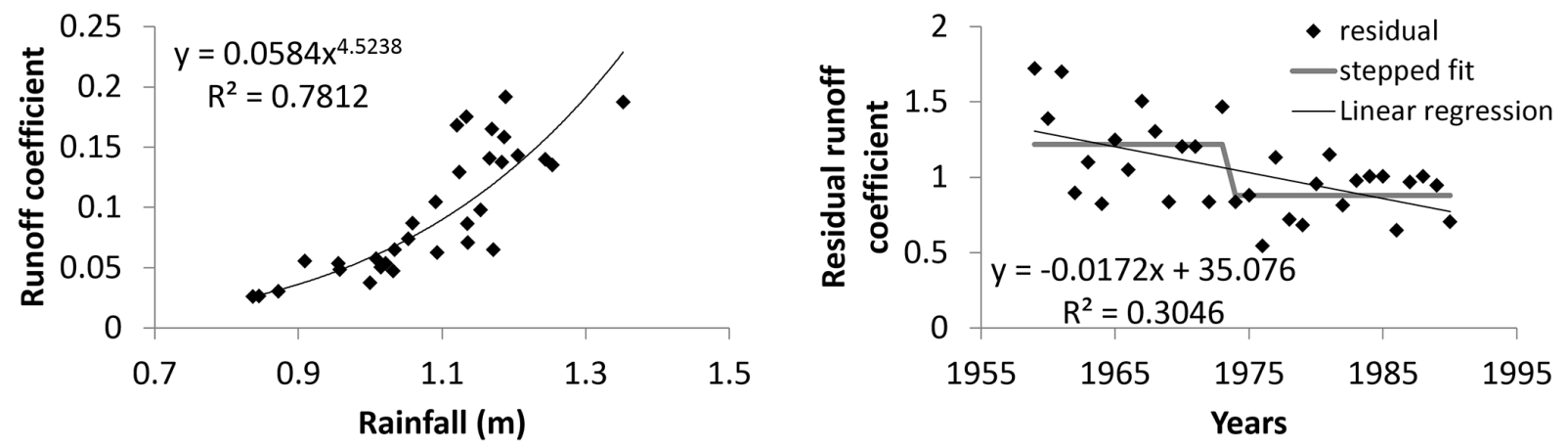

Figure 1. Variation in runoff coefficient with annual rainfall amount and time.

ulation growth in the Bani catchment, an exponential growth with time constant approximately 35 years is found. This has been used to explore whether anthropogenic drivers are important in modelling the change in the streamflow response of the catchment.

Before the mid 1980's, streamflow at the gauge site was perennial. After 1983, zero flows were recorded every year, extending typically from early April to mid-June. Annual peak flows show a downward trend with time, though this appears stepped, with decreases in the early 1970's and in 1982.

An investigation of the variation in the observed runoff coefficient with respect to annual rainfall shows the expected strong relationship, but with a large scatter at higher rainfall depths. Investigation of the change in runoff coefficient over time was carried out using the observed runoff coefficient divided by a fitted power law (termed here the residual runoff coefficient). Figure 1 shows the variation in the runoff coefficient with rainfall, and the decline in the residual runoff coefficient (runoff coefficient minus fit shown in first panel) over the observed period. This suggests either a gradual change in the catchment response from 1959-1990, or a step change in 1974, slightly later than the break at 1970 suggested by the analysis performed by Ruelland et al. (2008).

\section{Method}

A combination of data analysis and model testing/development has been used to detect evidence of variability in the response of the study catchment. The analysis is then used to explore ways of modifying the model to capture these variations.

\subsection{Data analysis}

Correlation analysis (Croke et al., 2011) is useful for exploring the average response of the catchment across the data period (or sub-sample if looking for changes in the response). The autocorrelation of streamflow can give information about the seasonality of rainfall, as well as the per- sistence of rainfall between time steps. The cross correlation between rainfall and streamflow gives insight into the catchment response, including the strength of the baseflow component and the seasonality of the streamflow.

\subsection{Model testing and development}

Based on the data analysis results, potential modifications to the model were hypothesised. These modifications were tested against the observed data, comparing with the performance of the original model in order to determine the impact of the modifications. Testing of the model performance was carried out in a number of ways (see review by Bennett et al., 2012 for an extensive discussion regarding the approaches for testing model performance):

- Plotting observed and modelled time series on both linear and log scales to see if there are particular aspects of the hydrograph that are not well represented;

- plotting model residuals against observed and modelled flow, as well as modelled effective rainfall (this gives insight into possible model deficiencies, particularly when residuals are plotted against observed flows);

- flow duration curve;

- model performance indicators, including the NashSutcliffe efficiency $\left(R^{2}\right.$, also called the coefficient of determination), $\log$ transformed $R^{2}$, and bias.

\section{Results and Discussion}

\subsection{Data analysis}

Cross correlation of the rainfall and streamflow data (Fig. 2) shows a strongly seasonal rainfall pattern, with the streamflow-rainfall correlation peak delayed by about 50 days, with slightly enhanced seasonality. This analysis shows the slow response of the catchment to rainfall events, and implies a standard UH model structure comprising of exponentially decaying stores arranged in parallel will not adequately 
Table 1. Parameter values for the Bani catchment.

\begin{tabular}{llrrr}
\hline Parameter & Description & $\begin{array}{r}\text { Lower } \\
\text { limit }\end{array}$ & $\begin{array}{r}\text { Upper } \\
\text { limit }\end{array}$ & Value \\
\hline$V_{1}$ & Proportion to first store & 0 & 1 & 0.1933 \\
$V_{2}$ & Proportion to second store & 0 & 1 & 0.7554 \\
$V_{3}$ & Proportion to third store & 0 & 1 & 0.0183 \\
$\tau_{1}$ & Time constant for first store & 0 & 10 & 2.4657 \\
$\delta$ & Delay & 0 & 30 & 0.9400 \\
$m$ & Number of stores & 1 & 12 & 3.8295 \\
\hline$L$ & Loss & 0 & 10 & 1.3028 \\
$d_{1}$ & First effective rain threshold & 20 & 1000 & 228.43 \\
$f$ & Stress threshold scale factor & 0.3 & 2 & 1.3233 \\
$n$ & Proportion to second threshold & 0 & 1 & 0.9442 \\
$d_{2}$ & Second effective rain threshold & 1.1 & 10 & 1.9787 \\
$e$ & Effective crop factor & 0.5 & 2 & 1.3845 \\
\hline
\end{tabular}

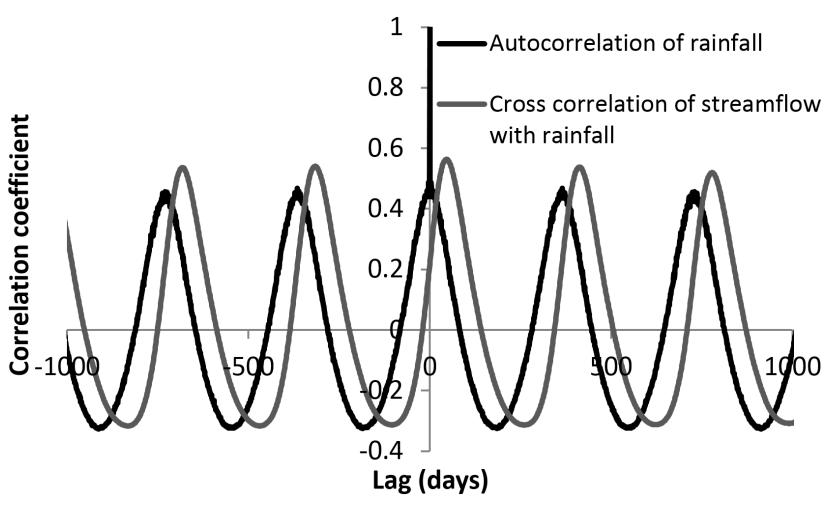

Figure 2. Correlation analysis of rainfall and streamflow data.

capture the hydrologic response of the catchment. Instead the model will require a cascade of stores; for example, a Nash Cascade, (Nash, 1960).

\subsection{Model development and testing}

Following the results described above, several modifications were made to the standard IHACRES model:

- a variation of the Nash Cascade used for the UH transfer function module to capture the slow rise to peak observed in the catchment response;

- a loss from the UH added to capture the transition from perennial to ephemeral flows.

\subsubsection{Unit Hydrograph structure}

The adopted structure of the UH involved a Nash cascade of identical compound stores (Fig. 3). Each compound store contained four exponentially decaying stores arranged in parallel, with the first time constant $\left(\tau_{1}\right)$ allowed to vary between 0 and 10 days, with the remaining three time con- stants fixed (16, 64 and 256 days). The other calibrated parameters in the UH module were partitioning between the components of each compound store $\left(V_{1}, V_{2}\right.$, and $V_{3}$, with $V_{4}=1-\left(V_{1}+V_{2}+V_{3}\right)$, the number of compound stores in the cascade $(m)$, and a delay $(\delta)$, giving a 6 parameter module. The number of compound stores is treated as a real number, with the fractional store corresponding to scaled time constants for each component store (modified time constant set to fraction component of $m$ times the original constant).

\subsubsection{Loss from Unit Hydrograph}

The loss from the streamflow is included in the last term in the Nash Cascade using a modified version of the approach by Ivkovic et al. (2009) and Herron and Croke (2009). This is done first as a loss from the slowest component, and then sequentially through the remainder of the stores until all stores were empty. Any further loss was then subtracted from all stores in proportion to the partitioning. The resulting negative value represents the water level in each store falling below the point where water is contributed to the streamflow, leading to a delay in the resumption of flow at the start of the next wet season.

Different sources of the loss term were explored, including subsurface outflow, evaporation loss as well as losses due to anthropogenic influences. A subsurface outflow was represented as a constant loss (i.e. will over-estimate the loss in dry conditions relative to wet conditions, and so would result in an over-estimation of the loss rate towards the end of the data period). Evaporation losses were simulated using a multiplication factor times the available potential evaporation data, where the multiplication factor represents the fraction of the catchment on which there is an evaporative loss from the groundwater systems. Thus, the evaporative loss option would be sensitive to changes in the potential evaporation, and so impacts by climate change/variability. Anthropogenic influences were represented as a scale factor times 


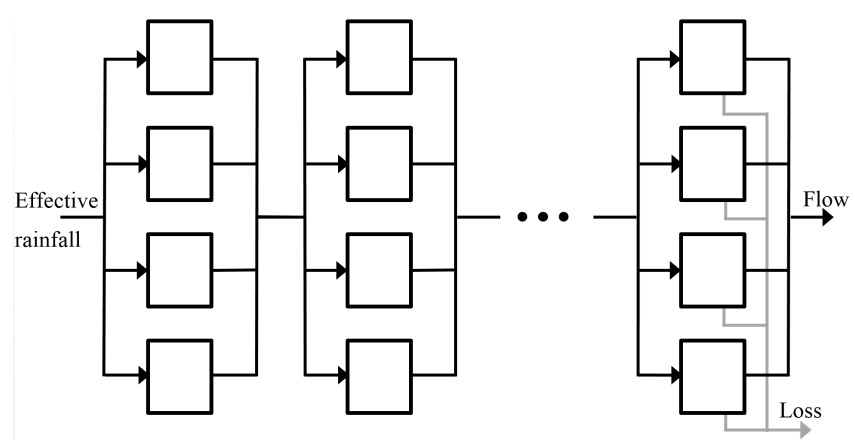

Figure 3. Unit Hydrograph model structure, including loss from last component of the cascade.

the population density growth through time. Analysis of the model results show that an increasing loss through time is needed to capture the transition from perennial to ephemeral flows. This increase cannot be captured using the potential evaporation data, suggesting that the main driver of the loss term is likely to be due to population growth (e.g. increased extractions).

\subsubsection{Modelled flows}

Combining the modified UH module, the loss from groundwater and the IHACRES CMD module gives a rainfallstreamflow model with 12 parameters. The modelled flows are shown in Fig. 4 and the parameter values shown in Table 1. Using the modified model, the values for most parameters showed modest variation though the data period (coefficient of variation $<5 \%$ ). The notable exception was the loss parameter, where the CV was approximately $100 \%$. The loss parameter is poorly defined in all but the last calibration period as this parameter is determined by the point where flows became ephemeral (post 1984). Note that the range of permitted values for the evaporation coefficient $(e)$ has been increased. This potentially indicates that a natural evaporative loss from the groundwater store is also necessary in more accurately represent the mass balance of the system.

\section{Conclusions}

Two changes to the traditional model structure were needed in order to capture the hydrological response of the Bani catchment:

- Modification of the unit hydrograph to use a Nash-like cascade of parallel stores;

- addition of a loss term that had an exponential growth.

The change to the unit hydrograph was necessary to enable a daily model to reproduce the slow response of the catchment to rainfall. The addition of the loss term was necessary to capture the transition of the river behaviour from perennial
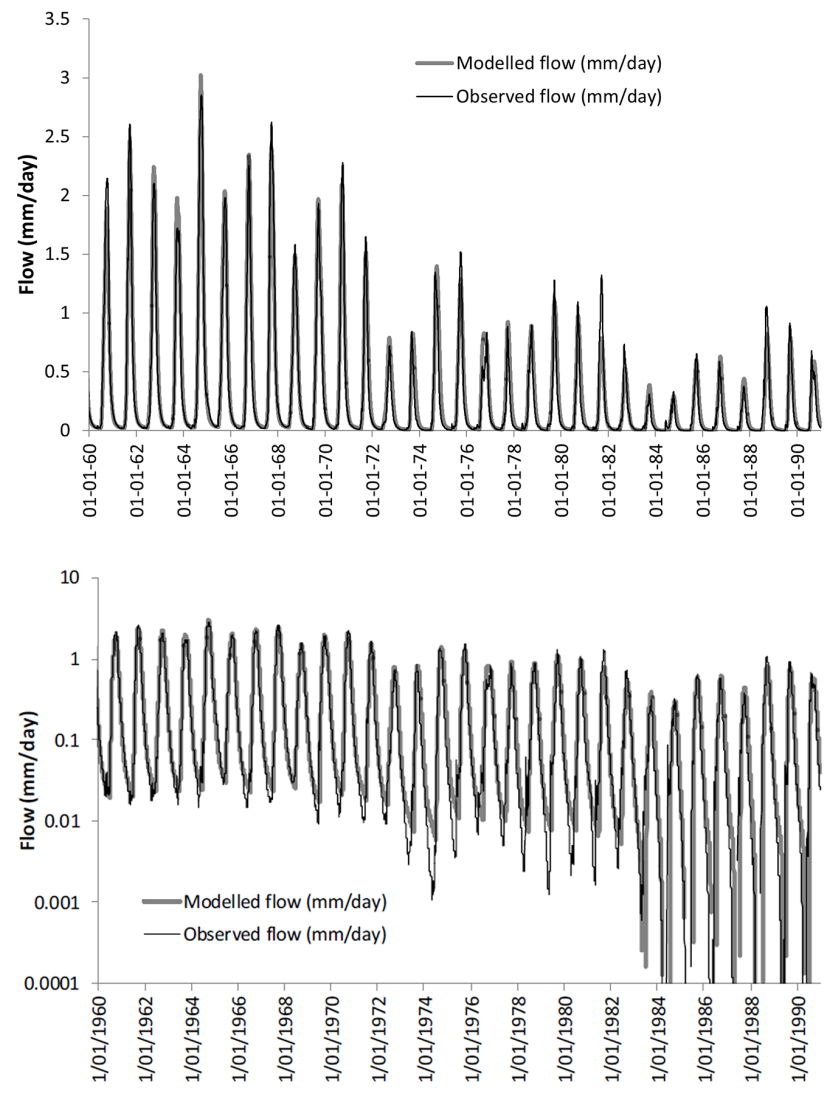

Figure 4. Comparison of modelled flows generated by modified model with the observed flows for the Bani catchment.

to ephemeral. This was found to be best captured by an exponential growth in the loss term, which suggests population growth may be a significant driver.

\section{The Supplement related to this article is available online at doi:10.5194/piahs-92-29-2015-supplement.}

Author contributions. B. F. W. Croke performed the data analysis, and developed the revised IHACRES model, and M.-J. Shin carried out simulations and sensitivity analysis using the original IHACRES model.

Acknowledgements. This work was supported by the Australian Research Council and the National Water Commission through the National Centre for Groundwater Research and Training. 


\section{References}

Andrews, F. T., Croke, B. F. W., and Jakeman, A. J.: An open software environment for hydrological model assessment and development, Environ. Modell. Softw., 26, 1171-1185, 2011.

Bennett, N. D., Croke, B. F. W., Guariso, G., Guillaume, J. H. A., Hamilton, S. H., Jakeman, A. J., Marsili-libelli, S., Newham, L. T. H., Norton, J. P., Perrin, C., Pierce, S. A., Robson, B., Seppelt, R., Voinov, A. A., Fathi, B. D., and Andreassian, V.: Characterising performance of environmental models, Environ. Modell. Softw., 40, 1-20, 2013.

Brigode, P., Oudin, L., and Perrin, C.: Hydrological model parameter unstability: A source of additional uncertainty in estimating the hydrological impacts of climate change, J. Hydrol., 476, 410425, 2013.

Chiew, F. H. A., Potter, N. J., Vaze, J., Petheram, C., Zhang, L., Teng, J., and Post, D. A.: Observed hydrologic non-stationarity in far south-eastern Australia: implications for modelling and prediction, Stoch. Environ. Res. Risk Assess., 28, 3-15, 2014.

Croke, B. F. W. and Jakeman, A. J.: A Catchment Moisture Deficit module for the IHACRES rainfall-runoff model, (plus Corrigendum to "A Catchment Moisture Deficit module for the IHACRES rainfall-runoff model" [Environ. Model. Softw. 19 (1) (2004) 15], 20, 977, 2005), Environ. Modell. Softw., 19, 1-5, 2004.

Croke, B. F. W., Islam, A., Ghosh, J., and Khan, M. A.: Evaluation of approaches for estimation of rainfall and the Unit Hydrograph, Hydrol. Res., 42, 372-385, 2011.

Herron, N. and Croke, B.: Including the Influence of Groundwater Exchanges in a Lumped Rainfall-Runoff Model, Math. Comput. Simulat., 79, 2689-2700, 2009.

Ivkovic, K. M., Letcher, R. A., and Croke, B. F. W.: Use of a simple surface-groundwater interaction model to inform water management, Aust. J. Earth Sci., 56, 71-80, 2009.
Jakeman, A. J., Littlewood, I. G., and Whitehead, P. G.: Computation of the instantaneous unit hydrograph and identifiable component flow with application to two small upland catchments, J. Hydrol., 117, 275-300, 1990.

Nash, J. E.: A unit hydrograph study with particular reference to British catchments, Proc. Institut. Civil Engin., 17, 249-282, 1960.

Oudin, L., Hervieu, F., Michel, C., Perrin, C., Andréassian, V., Anctil, F., and Loumagne, C.: Which potential evapotranspiration input for a rainfall-runoff model?, Part 2 - Towards a simple and efficient PE model for rainfall-runoff modelling, J. Hydrol., 303, 290-306, 2005.

Peel, M. C. and Blöschl, G.: Hydrological modelling in a changing world, Prog. Phys. Geogr., 35, 249-261, 2011.

Refsgaard, J. C., Madsen, H., Andréassian, V., Arnjerg-Nielsen, K., Davidson, T. A., Drews, M., Hamilton, D. P., Jeppesen, E., Kjellström, E., Olesen, J. E., Sonnenborg, T. O., Trolle, D., Willems, P., and Christensen, J. H.: A framework for testing the ability of models to project climate change and its impacts, Clim. Change, 122, 271-282, 2014.

Ruelland, D., Ardoin-Bardin, S., Billen, G., and Servat, E.: Sensitivity of a lumped and semi-distributed hydrological model to several methods of rainfall interpolation on a large basin in West Africa, J. Hydrol., 361, 96-117, 2008.

Ruelland, D., Levavasseur, F., and Tribotte, A.: Patterns and dynamics of land-cover changes since the 1960s over three experimental areas in Mali, Int. J. Appl. Earth Obs., 120, 511-517, 2010.

Ruelland, D., Ardoin-Bardin, S., Collet, L., and Roucou, P.: Simulating future trends in hydrological regime of a large SudanoSahelian catchment under climate change, J. Hydrol., 424/425, 207-216, 2012. 